\title{
UMA PROPOSTA DE ENSINO DO EFEITO FOTOELÉTRICO UTILIZANDO SIMULAÇÃO COMPUTACIONAL A PARTIR DOS TRÊS MOMENTOS PEDAGÓGICOS
}

\section{FRANCISCO DE ASSIS LIMA DE SOUSA JUNIOR}

Instituto Federal do Rio de Janeiro

E-mail: fassis@metalmat.ufrj.br

\section{MARCUS VinÍCIUS PEREIRA}

Instituto Federal do Rio de Janeiro

E-mail: marcus.pereira@ifrj.edu.br

\section{RESUMO}

O currículo de física no ensino médio, durante muitos anos, se encontrava restrito à abordagem de tópicos pertencentes à física clássica e atualizações curriculares a partir do final do século XX introduziram tópicos de Física Moderna e Contemporânea (FMC). O efeito fotoelétrico, um dos tópicos de FMC, trata-se de um fenômeno abstrato e de difícil observação e compreensão pelos estudantes, gerando um obstáculo para a sua aprendizagem. O objetivo deste trabalho é identificar as contribuições de uma sequência didática envolvendo o uso de simulações computacionais para o processo de ensino e aprendizagem do efeito fotoelétrico tendo por base os três momentos pedagógicos. A estratégia foi aplicada durante quatro aulas de uma turma da 3a série do ensino médio de um colégio localizado no município de Nova Iguaçu (RJ). Os dados foram coletados por meio de gravação em áudio dessas aulas, questionários e a prova bimestral da escola e foram analisados através do método da análise de conteúdo. Como resultados, podemos citar que houve uma evolução gradativa nas respostas dos questionários no decorrer da intervenção didática, aumento da capacidade de aplicação dos conhecimentos em situações reais e preferência por aulas com a simulação computacional pela maioria dos estudantes.

\section{PALAVRAS-CHAVE:}

efeito fotoelétrico, simulação computacional, três momentos pedagógicos. 


\begin{abstract}
:
The high school physics curriculum for many years was restricted to the approach of classical physics and curricular updates since the end of twentieth century introduced modern and contemporary physics topics as photoelectric effect, an abstract phenomenon which is difficult to observe and understand by students, creating an obstacle to learning. The objective of this work is to identify the contributions of a didactic sequence involving the use of computational simulations for the teaching and learning process of the photoelectric effect based on the three pedagogical moments. The strategy was applied during four classes of a high school located in Nova Iguaçu (RJ). Data were collected through audio recording of these classes, questionnaires and the a written exam and were analyzed through the content analysis method. As results, we can mention that there was a gradual evolution in the answers of the questionnaires during the didactic intervention, increase of the capacity of application of the knowledge in real situations and preference for classes with the computer simulation by most of the students.
\end{abstract}

\title{
KEYWORDS:
}

photoelectric effect, computational simulation, three pedagogical moments.

\section{INTRODUÇÃO}

A inserção de tópicos de Física Moderna e Contemporânea (FMC) no Ensino Médio (EM) vem sendo cada vez mais discutida no meio acadêmico, consolidando-se como uma linha de pesquisa na área de ensino de física (SILVA, ARENGHI e LINO, 2013). Trata-se de uma parte da Física que representou uma ruptura do pensamento clássico, que se tornou limitado frente às descobertas que surgiram a partir do século XX, promovendo, assim, um avanço no conhecimento científico com o qual não poderia ser alcançado sem os novos conceitos e teorias propostos pelos cientistas dessa época. De acordo com um levantamento realizado por Silva, Arenghi e Lino (2013), as justificativas mais frequentemente encontradas em trabalhos acadêmicos que abordem a inclusão de tópicos de FMC nos currículos escolares são: (i) importância na compreensão das tecnologias da atualidade; (ii) a FMC representou uma mudança de paradigma da Física dando uma importante noção de 
desenvolvimento das ciências; (iii) a FMC como subsídio à compreensão crítica das questões atuais que envolvem ciência, tecnologia, sociedade e ambiente.

As pressões do meio acadêmico que se refletem nas esferas decisórias em termos de políticas curriculares e editoriais para que sejam inseridos no EM conteúdos relacionados à $F M C$ começaram a surtir efeito nas escolas públicas estaduais do Rio de Janeiro. O Currículo Mínimo (CM), recentemente implementado em pela Secretaria de Estado de Educação do Rio de Janeiro (SEEDUC-RJ), apresenta tópicos de FMC distribuídos nas três séries do EM (RIO DE JANEIRO, 2012), e o Sistema de Avaliação do Estado do Rio de Janeiro (SAERJ) exige a aprendizagem desses conteúdos. Porém, apesar dos esforços, esbarramos ainda na falta de qualificação dos docentes para trabalharem esses conteúdos em sala de aula. Monteiro e Nardi (2009) afirmam que muitos professores, após a formação inicial, ainda não adquirem autonomia suficiente para ensinar FMC no EM. Os tópicos de FMC, durante a formação inicial, geralmente, são trabalhados de maneira desvinculada da sala de aula da educação básica, com uma linguagem complexa e matemática incompatível e não problematizada com o nível de ensino para o qual o licenciando está sendo formado.

As aulas prático-experimentais, que poderiam ajudam a minimizar tais problemas, esbarram na necessidade de um laboratório equipado e, em especial, no caso dos fenômenos relacionados à FMC, os equipamentos experimentais são de grande porte ou de difícil observação detalhada (SOARES, MORAES e OLIVEIRA, 2015). Soma-se, ainda, a esse entrave, as condições de trabalho de grande parte dos professores no cenário educacional brasileiro para desenvolver atividades práticoexperimentais nas escolas, que demandam "organização e disponibilidade [...], especialmente quando ele não é dedicado exclusivamente às aulas de laboratório, fato comum em grande parte das escolas brasileiras, e ainda mais quando precisa 
trabalhar em mais de uma escola e com condições cada vez mais desfavoráveis" (PEREIRA e MOREIRA, 2017, p.271).

Um tópico importante dentro da FMC e considerado por muitos como a pedra fundamental da física quântica é o efeito fotoelétrico, fenômeno que não é facilmente reproduzido em sala de aula. Uma alternativa utilizada para auxiliar os docentes nessa empreitada é o uso de simuladores computacionais, que podem ajudar na compreensão dos conceitos envolvidos, além de possuir aspecto motivacional ao trazer dinamismo e praticidade às aulas. Por outro lado, se não planejada, a sua utilização pode criar um clima de deslumbramento por parte do professor e/ou dos alunos que pode se distanciar do principal objetivo que é a aprendizagem, sobretudo quando a simulação é vista apenas de maneira contemplativa (MEDEIROS e MEDEIROS, 2002). Dessa maneira, um simulador pode suprir, inclusive, a ausência de laboratórios e equipamentos ao se ensinar determinados tópicos (CARDOSO e DICKMAN, 2012).

Dessa forma, buscamos identificar as contribuições, para o processo de ensino e aprendizagem do efeito fotoelétrico, de uma sequência didática que faça uso de recursos como imagens e simulações computacionais pré-selecionadas. Essa sequência didática foi elaborada com base no método didático-pedagógico chamado de Três Momentos Pedagógicos (3MP) de Gehlen, Maldaner e Delizoicov (2012), que defende uma abordagem dialógica.

\subsection{Problematização}

Segundo Ostermann e Moreira (2001), é preciso elaborar um maior número de materiais acessíveis aos professores e associados aos cursos de formação inicial e continuada. Esses autores consultaram diversos materiais de ensino de FMC e observaram que esses se caracterizam por serem densos e demandarem conhecimentos prévios que apenas especialistas na área possuem. Para Brockinton e 
Pietrocola (2005), a dificuldade de se ensinar FMC no EM com qualidade é devida principalmente à utilização da mesma forma de transposição didática usada para o ensino da física clássica. Essa prática acaba por transformar um exercício sobre partículas elementares em um problema de colisões de bolinhas, ou seja, apenas mudando os nomes dos elementos envolvidos. Paulo e Moreira (2011) apontam o problema da linguagem, enquanto conjunto de signos com o qual nos comunicamos e construímos conhecimento, como um dos aspectos que dificultam a abordagem da física quântica no EM. Ostermann e Moreira (2000) indicam três vertentes representativas de abordagens metodológicas para a introdução de FMC no EM têm sido consideradas: (i) exploração dos limites clássicos, (ii) não utilização de referência aos modelos clássicos e (iii) escolha de tópicos essenciais. Enquanto alguns autores criticam o uso de analogias clássicas no ensino de FMC, outros consideram que a sustentação na física clássica e a escolha de poucos mas importantes tópicos facilitam a aprendizagem de FMC.

Em um levantamento bibliográfico de artigos publicados no período compreendido entre 2011 e 2016 sistematizado em cinco periódicos nacionais Caderno Brasileiro de Ensino de Física (CBEF), Ciência \& Educação (C\&E), Investigações em Ensino de Ciências (IENCI), Revista Brasileira de Ensino de Física (RBEF) e Revista Brasileira de Pesquisa em Educação em Ciências (RBPEC) - foram selecionados 131 artigos relacionados à FMC dos 1.565 publicados. Identificamos o termo "efeito fotoelétrico" em 23, que foram lidos a fim de identificar com que objetivo era feita a menção, e apenas cinco desses visavam contribuir com o ensino do efeito fotoelétrico, a saber: Silva e Errobidart (2015); Cardoso e Dickman (2012); Silva e Assis (2012); Cavalcante, Rodrigues e Bueno (2013); Sabino e Pietrocola (2016). No Quadro 1 abaixo são apresentados os resultados quantitativos desse levantamento. É interessante notar que, apesar da RBEF apresentar o maior 
quantitativo de artigos que cita o efeito fotoelétrico (12), nenhum deles problematiza o ensino desse assunto, que aparece apenas em quatro artigos publicados no CBEF e em um artigo publicado na IENCI.

Quadro 1: Distribuição do número de artigos sobre o Efeito Fotoelétrico por revistas. Fonte: Autores.

\begin{tabular}{|c|c|c|c|c|}
\hline \multirow[b]{2}{*}{ PERIÓDICO } & \multicolumn{4}{|c|}{ NÚMERO DE ARTIGOS PUBLICADOS } \\
\hline & Geral & Sobre FMC & $\begin{array}{l}\text { Cita o efeito } \\
\text { fotoelétrico }\end{array}$ & $\begin{array}{l}\text { Sobre o ensino do } \\
\text { efeito fotoelétrico }\end{array}$ \\
\hline RBEF & 567 & 92 & 12 & 0 \\
\hline CBEF & 257 & 26 & 9 & 4 \\
\hline C\&E & 364 & 5 & 0 & 0 \\
\hline $\mathrm{IENCl}$ & 181 & 4 & 1 & 1 \\
\hline RBPEC & 196 & 4 & 1 & 0 \\
\hline TOTAL & 1.565 & 131 & 23 & 5 \\
\hline
\end{tabular}

Silva e Errobidart (2015) realizaram uma pesquisa bibliográfica e destacaram diversas propostas de abordagem e também aspectos que devem ser considerados ao se trabalhar esse tema no EM. Já Cardoso e Dickman (2012) propuseram uma sequência didática com a utilização de uma simulação computacional aliada à teoria da aprendizagem significativa e relatam ter alcançado resultados satisfatórios na aprendizagem do assunto ensinado. Em outros dois artigos, de Silva e Assis (2012) e de Cavalcante, Rodrigues e Bueno (2013), o princípio de funcionamento de um mesmo aparelho, o controle remoto, foi utilizado como estratégia de ensino do efeito fotoelétrico e ambos apontaram aspectos como o motivacional e a relação da física com as tecnologias atuais. Sabino e Pietrocola (2016) investigaram dois professores durante a aplicação de uma sequência didática sobre dualidade ondapartícula com alunos da 3a série do EM e encontraram resultados distintos para cada docente, e indicaram que o sucesso da aplicação de uma estratégia didática, por 


\section{DE Eebates

mais inovadora que seja, depende da maneira com que o docente a incorpora. Esses artigos, mesmo caracterizando um conjunto pequeno, representam a produção sobre o ensino do efeito fotoelétrico nos últimos seis anos e trazem referências a vários outros trabalhos importantes publicados em período anterior.

Muitos pesquisadores defendem a utilização sistemática das simulações nas salas de aulas, inclusive apontando inúmeros benefícios que esse recurso traz para o ensino de física, como: motivar os alunos, aumentando o interesse nas aulas, o engajamento em atividades propostas pelo professor e a concentração nos conceitos envolvidos; aperfeiçoar a compreensão dos conceitos, pois fornecem um feedback; tornar conceitos abstratos mais concretos, ajudando a construir uma possível mudança conceitual; permitir a coleta de grande quantidade de dados rapidamente (MEDEIROS e MEDEIROS, 2002). Longe de construir uma panaceia, há alguns aspectos que podem transformar esse recurso em um vilão. O primeiro e mais simples deles é o fato de que o processo de ensino e aprendizagem é altamente complexo, não se resumindo a utilização de uma única estratégia ou recurso para garantir o seu sucesso. Outro aspecto a ser considerado diz respeito à natureza da simulação computacional. Toda simulação é um modelo simplificado do real, construído através de um banco de dados que por maior que seja não dá conta de infinitas possibilidades. Esse modelo está baseado em pressupostos definidos pelo criador da simulação e ficam implícitos nela, além de limitar o alcance da própria simulação na explicação de outras situações (MEDEIROS e MEDEIROS, 2002). Apesar dessas limitações, a simulação computacional vem sendo cada vez mais utilizada pelos professores e a experiência em sala de aula tem mostrado que há boa aceitação por parte dos estudantes. 


\section{DE Eebates \\ em Educação Científica e Tecnológica \\ ISSN - 2236-2150 (Eletrônica)}

\subsection{FUNDAMENTAÇÃO TEÓRICA}

O método didático-pedagógico conhecido como Três Momentos Pedagógicos (3MP) foi desenvolvido originalmente por Delizoicov e Angotti ainda no início dos anos 1980 e tinha como objetivo principal a elaboração de um currículo de física baseado em temas geradores de acordo com a perspectiva de Paulo Freire para a educação. Apesar de primeiramente organizar o currículo a partir de temas geradores, esse método sofreu algumas mudanças, chegando a uma tendência mais atual de organizar os conteúdos disciplinares de acordo com a estrutura conceitual da disciplina ou área de conhecimento. Nesse trabalho, nos apoiamos em trabalho mais atual publicado por Gehlen, Maldaner e Delizoicov (2012), que defendem que a dinâmica dos 3MP se caracteriza por três fases consecutivas:

1. Problematização Inicial. Fase em que são apresentadas questões ou situações reais que os alunos vivenciam e tem envolvimento com o tema escolhido, buscando conhecer o que os alunos pensam e sabem sobre o assunto. É o momento apenas de questionamento não devendo ser dada resposta alguma aos alunos. Por vivenciarem até mesmo cotidianamente essas situações apresentadas pelo professor, os alunos muitas vezes nunca se deram conta ou nunca se perguntaram como solucionar essas questões e quais as consequências delas. Portanto, o objetivo da problematização inicial é promover um distanciamento crítico em relação ao problema proposto, fazendo com que o mesmo sinta a necessidade de buscar novos conhecimentos.

2. Organização do Conhecimento. Nesta fase, os conhecimentos científicos são confrontados com os conhecimentos prévios dos alunos. É o estudo sistemático dos conteúdos e conceitos necessários para a compreensão do(s) tema(s), sob a orientação do professor. Para isso, o docente deve consultar diversas fontes de conhecimento e utilizar diversos materiais e recursos didáticos que auxiliem na 
abordagem dos conteúdos. Atividades também fazem parte desta etapa, pois ajudam a organizar a aprendizagem.

3. Aplicação do Conhecimento. Fase em que o aluno utiliza o conhecimento construído nas etapas anteriores para interpretar e analisar tanto as situações apresentadas pelo professor quanto outras que possam ser compreendidas a partir do mesmo conhecimento. As questões iniciais retornam e os alunos passam a relacioná-las com os conceitos estudados, criando condições de solucionar o problema inicial. O professor pode aproveitar esse momento para novos questionamentos e, assim, promover um aprofundamento do tema abordado (ALBUQUERQUE, SANTOS e KAIANA, 2015).

A aplicação do método dos 3MP vem crescendo nos últimos anos, porém, segundo Delizoicov (2008), o uso mecânico desses momentos apenas com o objetivo de organizar as aulas, fazendo da problematização inicial um simples pretexto para introduzir o tema na fase de organização do conhecimento, é uma prática que não deve acontecer. Várias são as possibilidades de se incorporar recursos didáticos, assim como várias são as maneiras de se trabalhar com o método dos 3MP, desde a organização de sequências didáticas numa visão microscópica, até a estruturação curricular de uma disciplina numa visão macroscópica. De maneira geral, em todas busca-se uma identificação do estudante com o que será ensinado e uma constante dialogicidade entre os sujeitos envolvidos, professor e aluno.

\section{MetOdologia}

A pesquisa tem natureza qualitativa com abordagem participante, e buscou-se confrontar o método tradicional de ensino, caracterizado por uma abordagem unilateral em que o professor transmite o conhecimento aos alunos através de aulas predominantemente expositivas com pouco ou até nenhum espaço para questionamentos, com um método que privilegia a discussão e a experimentação. 
Para isso, observamos o comportamento e o desempenho dos alunos frente a essas duas abordagens para detectar indícios de uma melhor aceitação por uma delas, ou até mesmo pelas duas simultaneamente.

Os procedimentos metodológicos de coleta e análise dos dados seguiu um planejamento que levou em consideração às etapas do método de análise de conteúdo de Bardin (2009), fazendo uma descrição do conteúdo contido em textos, entrevistas e outros tipos de materiais, através de procedimentos sistemáticos e objetivos (MINAYO, 2008). A coleta de dados envolveu o uso de instrumentos como gravação das falas dos alunos, registro das respostas escritas por eles em questionários e na prova bimestral final, além de textos dissertativos. Esses dados foram então submetidos à pré-análise, e, após isso, buscamos padrões de respostas que pudessem culminar em indicadores que fundamentassem uma interpretação final no processo de pesquisa que conduzimos. A partir daí, fizemos uma análise para cada fase, classificando as respostas de acordo com os conceitos envolvidos e a compreensão dos mesmos por parte os alunos. Também verificamos a frequência com que algumas delas apareceram, com o objetivo de obter um panorama global da turma com relação a aprendizagem do tema, por mais que o objetivo da pesquisa não seja qualquer generalização a partir de um estudo quantitativo.

A sequência didática foi aplicada pelo próprio pesquisador (primeiro autor deste artigo) como produto educacional de sua dissertação de mestrado profissional em uma turma da 3a série do EM dessa escola, localizada no município de Nova Iguaçu, que adota divisão do ano letivo em quatro bimestres e um sistema de avaliação bimestral que consiste em trabalho (teste), simulado e prova, nos quais os alunos devem ter contato com questões abordadas nos principais exames. Apesar disso, o professor tem liberdade de propor atividades de pesquisa e projetos de aplicação dos conteúdos trabalhados em sala de aula para avaliar os alunos. 
A escola disponibiliza dois tempos consecutivos por semana para as aulas de física, cada um deles com duração de 50 minutos, e, em termos de infraestrutura, a escola não possui laboratório, mas conta com um projetor digital e um computador portátil. O programa de física para a $3^{a}$ série do EM apresenta a clássica divisão: eletrostática, eletrodinâmica, magnetismo e FMC, nesta ordem, respectivamente, para os quatro bimestres do ano letivo. A turma da 3ª série no ano de 2016 possuía 24 alunos e todos consentiram em participar da pesquisa assinando um termo.

O planejamento da estratégia didática envolveu sua aplicação em quatro aulas (oito tempos de 50 minutos, perfazendo uma carga horária total de aproximadamente 7 horas) consecutivas do $4^{\circ}$ bimestre letivo da turma de $3^{a}$ série do EM. O professor/pesquisador seguiu um roteiro em que os 3MP foram estruturados entre as quatro aulas da seguinte forma:

- Problematização Inicial. Alguns exemplos de sistemas tecnológicos que utilizam o efeito fotoelétrico foram responsáveis pela contextualização inicial, quando o professor, na primeira aula, trouxe esses exemplos com o objetivo de estimular a curiosidade e o interesse da turma para depois inserir a pergunta: Como funcionam esses sistemas? As respostas dadas por cada estudante foram registradas em forma dissertativa e entregues escritas em papel ao professor.

- Organização do Conhecimento. Nesta fase ocorreu a abordagem sistemática dos conteúdos relacionados ao tema e foi executada em dois dias: no primeiro, de maneira tradicional, utilizando o quadro negro, textos e/ou slides, e, no segundo, fazendo uso do simulador computacional do PhET como recurso didático. Ao final de cada um desses dias, um mesmo trabalho contendo questões sobre o efeito fotoelétrico foi aplicado para aferir a aprendizagem dos alunos nesses dois momentos. 
- Aplicação do Conhecimento. Neste momento o professor retornou à pergunta feita no momento da Problematização Inicial a fim de que os alunos aplicassem os conhecimentos adquiridos na etapa de Organização do Conhecimento, na tentativa de respondê-la. Para isso, foi utilizado um outro simulador computacional educativo que consiste em fazer sistemas eletrônicos como portas automáticas e alarmes de segurança funcionar através da montagem dos seus circuitos elétricos.

\section{RESULTADOS E DISCUSSÃO}

No primeiro momento pedagógico, a Problematização Inicial, quando os alunos possuíam poucas noções sobre o efeito fotoelétrico, predominaram ideias ingênuas, mas também algumas mais elaboradas. Esse momento, realizado em uma aula, foi dividido em dois passos. No primeiro, procedemos com os estudantes à leitura de um texto sobre o efeito fotoelétrico citando algumas das suas aplicações, porém sem definir e sem explicar como ocorrem essas aplicações. Esse texto, intitulado "O efeito fotoelétrico no cotidiano", consta do produto educacional desenvolvido. Em seguida, fizemos a apresentação de três dispositivos que utilizam o conceito do efeito fotoelétrico - porta automática, poste de iluminação e câmera digital - seguida de uma discussão de como eles funcionam.

Durante a discussão, após a leitura do texto, os estudantes se manifestaram e destacamos algumas falas que demonstraram uma diferença entre pensamentos mais equivocados, baseados no senso comum, e outros mais elaborados, mesmo que ainda confusos, mas que mais se aproximavam do conceito aceito pela ciência. Nessa etapa, como foi realizada uma discussão livre e em grupo com todos os alunos da turma, optamos por não identificar a fala de cada um.

Os dois (poste e porta automática) possuem sensores, um de calor e outro de movimento. 
Calor, ele detecta o calor do corpo e abre a porta.

A luz está ativando esses sistemas.

No poste tem uma fotocélula.

Sensor que emite luz em uma área que, se você entrar, ele limita a conexão.

Tem uma área que consegue atingir a luz. Quando entra na frente da luz fica escuro e não atinge a base de influência da luz aí não consegue ligar.

No segundo passo, uma breve explicação de como cada dispositivo funciona foi dada, seguida de um questionário contendo três perguntas básicas: Como funciona cada um desses sistemas (porta automática, poste e câmera digital)? O que eles têm em comum? Que descoberta feita pela ciência você acha que foi essencial para a construção desses sistemas? Após a explanação inicial, cada estudante registrou sua resposta às três perguntas e, no Quadro 2 a seguir, transcrevemos algumas delas. Como as respostas foram dadas em forma escrita e individual, pudemos fazer a identificação, de forma que cada aluno, doravante, será denominado pela letra " $A$ " acompanhada do número que identifica um mesmo aluno: $A 1, A 2, A 3$ etc. 
Quadro 2: Respostas dos alunos às perguntas do professor na fase de Problematização Inicial. Fonte: Autores.

\begin{tabular}{|c|c|}
\hline PERGUNTA & RESPOSTA \\
\hline $\begin{array}{l}\text { Como funciona cada um desses } \\
\text { sistemas (porta automática, poste e } \\
\text { câmera digital)? }\end{array}$ & $\begin{array}{l}\text { Porta automática } \\
\text { Funciona com um sensor de proximidade que utiliza um infravermelho } \\
\text { para captar o calor do corpo para fazer com que ela abra. (A1) } \\
\text { Funciona principalmente pelo sensor e corrente elétrica. Um feixe de luz } \\
\text { infravermelho atinge o receptor o qual está gerando corrente elétrica. Ao } \\
\text { passar por esse sensor que emite luz, a corrente elétrica para de } \\
\text { funcionar, abrindo automaticamente a porta. (A2) } \\
\text { Poste } \\
\text { Existe como se fosse uma caixa, uma célula fotoelétrica onde armazena a } \\
\text { luz durante o dia e à noite, ao existir a ausência de luz, o poste acende } \\
\text { automaticamente. (A3) } \\
\text { Exige também corrente e uma bobina, a qual gera um campo elétrico. A } \\
\text { noite, sem a corrente elétrica a chave se fecha e a luz acende. (A2) } \\
\text { Câmera digital } \\
\text { Tem um dispositivo que monta a imagem e a emite no visor. (A4) } \\
\text { formar números binários para a formação da imagem. (A5) }\end{array}$ \\
\hline O que eles têm em comum? & $\begin{array}{l}\text { Todos utilizam a luz como forma de energia... (A6) } \\
\text { Cada um transforma a luz em alguma forma de eletricidade. (A1) } \\
\text { A luz ativa circuitos que geram corrente elétrica, campo magnético e } \\
\text { sensores de imagem. (A7) }\end{array}$ \\
\hline $\begin{array}{l}\text { Que descoberta feita pela ciência você } \\
\text { acha que foi essencial para a construção } \\
\text { desses sistemas? }\end{array}$ & $\begin{array}{l}\text { A luz como fonte de energia. (A6) } \\
\text { A descoberta da captura de luz em aparelhos eletrônicos. (A8) } \\
\text { A capacidade da luz de trabalhar junto a outros sistemas, gerando } \\
\text { corrente elétrica. (A7) }\end{array}$ \\
\hline
\end{tabular}

Analisando as respostas, notamos que, mesmo após uma breve explicação do professor, algumas concepções a respeito do funcionamento desses dispositivos ainda continuaram equivocadas como a ideia do armazenamento da luz, 
confundindo-a como uma forma de energia. Porém, alguns alunos perceberam que é possível gerar corrente elétrica a partir da incidência da luz e, assim, alimentar um circuito realizador de trabalho. De acordo com os objetivos da Problematização Inicial, conseguimos, por meio do debate e dos questionamentos, promover a contextualização do tema junto aos alunos, mostrar que muitas das tecnologias com que os estudantes convivem diariamente têm origem em descobertas feitas pela ciência, induzir os alunos a pensar em como funcionam equipamentos e dispositivos que eles manuseiam ou interagem e fazê-los se interessar em aprender o mecanismo de funcionamento desses e de outros equipamentos.

O segundo momento pedagógico, denominado Organização do Conhecimento, foi executado em duas aulas distintas. Na primeira aula, o histórico do efeito fotoelétrico, passando pela investigação e conclusões de Lenard até se chegar ao modelo proposto por Einstein, foi apresentando por meio de uma apresentação em projetor digital. Além de trabalhar os conceitos relacionados ao efeito fotoelétrico, a aula também teve como objetivo confrontar ideias da física clássica com as novas ideias que emergiram com a física moderna. Observamos que os alunos tiveram o mesmo comportamento de outras aulas, ou seja, poucas perguntas e colocações, porém demonstraram vontade de aprender sobre o assunto, visto que a grande maioria se concentrou na exposição do professor, não havendo dispersão em conversas paralelas.

Apesar de utilizarmos slides contendo figuras e até um pequeno vídeo sobre o detector de ondas eletromagnéticas de Hertz, os alunos apresentaram problemas de abstração e entendimento das situações e fenômenos, mostrando ser o assunto completamente novo para eles. As respostas, mesmo com um razoável nível de acertos, denotaram uma assimilação mecânica do conteúdo caracterizada por frases decoradas da fala do professor e com pouca capacidade de aplicação desse 


\section{DEDebates

conhecimento. Percebemos, também, algumas poucas respostas muito precisas e com uma linguagem científica incomum entre os alunos, causando certa desconfiança de que a resposta possa ter sido pesquisada rapidamente na internet sem que o professor percebesse. Também encontramos dificuldades em categorizar as respostas, pois algumas continham duas perguntas na mesma questão e outras que poderiam não estar claras para o aluno, configurando-se em uma falha na elaboração do instrumento de pesquisa, que não pode ser validado anteriormente.

No segundo dia da etapa de Organização do Conhecimento, uma aula foi ministrada utilizando somente a simulação do efeito fotoelétrico do $\mathrm{PhET}^{1}$, seguindo a sequência abaixo:

1. Definição das grandezas. Manipulamos a simulação, variando a intensidade e o comprimento de onda da radiação luminosa, modificamos o material das placas metálicas utilizando o sódio, o zinco e o cobre, alteramos a voltagem da bateria e assim mostramos a função de cada uma dessas grandezas, porém ainda sem gerar o efeito fotoelétrico.

2. Gerando o efeito fotoelétrico. Fizemos a demonstração do fenômeno usando parâmetros pré-estabelecidos, simultaneamente íamos pedindo aos alunos que descrevessem o que estavam observando e enfim definimos o conceito de efeito fotoelétrico. Também fizemos as perguntas: Que bolinhas são essas que saem de uma placa em direção à outra? O que acontecerá se aumentarmos a intensidade da radiação? E o seu comprimento de onda?

3. Explicando o modelo. Discutimos com os alunos como fazer para gerar o efeito fotoelétrico na simulação, ou seja, eles sugeriam ações e nós as executávamos explicando o que estava dando errado até conseguirmos. Trabalhamos também 
as inconsistências com a Física Clássica, por exemplo, ao aumentar a intensidade da radiação o efeito não ocorria para determinados comprimentos de onda e quando ocorria, a velocidade das bolinhas também não crescia. Definimos o conceito de frequência de corte e explicamos o modelo proposto por Einstein utilizando a opção "mostrar fótons" na simulação.

4. Atividades. Manipulando a simulação com a ajuda dos alunos, encontramos o valor da frequência de corte para cada um dos materiais disponíveis, fizemos a relação entre a intensidade da radiação e a corrente elétrica concluindo serem diretamente proporcionais. Por fim, realizamos a verificação da equação de Einstein medindo e calculando as variáveis envolvidas.

A ideia inicial era conseguir alguns tablets ou notebooks para que o roteiro contido no produto educacional fosse seguido ao mesmo tempo em que o professor mostrava no projetor digital e as atividades fossem realizadas em grupo. Alguns alunos trouxeram tablets, mas em nenhum deles foi possível executar a simulação por não possuírem programas compatíveis com a linguagem Java em que é programada a simulação. Além disso, o sinal da internet disponibilizada pela escola não alcançava a sala de aula, impossibilitando assim a utilização da simulação diretamente do seu website. Com isso, a interatividade dos alunos com a simulação ficou comprometida e todos tiveram que apenas assistir a manipulação da simulação realizada pelo professor, que simultaneamente ia questionando e discutindo as situações de acordo com o que estava descrito no produto educacional.

Ao final da aula, aplicamos o mesmo teste da primeira aula, apenas substituindo a questão 6 por outra também de cálculo e incluímos na pergunta 5 a definição do potencial de corte, além de frequência de corte e função trabalho. No Quadro 3 abaixo selecionamos algumas das respostas dadas pelos estudantes nesta etapa. 
Quadro 3: Exemplos de respostas que evoluíram conceitualmente. Fonte: Autores.

\begin{tabular}{|l|l|}
\hline QUESTÃO & \begin{tabular}{l} 
EXEMPLO DE RESPOSTA \\
\hline 2
\end{tabular} \\
\hline 2 & $\begin{array}{l}\text { Quando uma placa fica exposta a uma radiação, dependendo da frequência, essa } \\
\text { consegue arrancar elétrons dessa placa. (A2) } \\
\text { radiação e da frequência. (A1) }\end{array}$ \\
\hline 3 & $\begin{array}{l}\text { Porque dizia que não deveria depender da frequência da onda. (A10) } \\
\text { fosse arrancado. Com a chuva de balas, arrancaria mais fácil os elétrons. (A2) }{ }^{2}\end{array}$ \\
\hline 5 & $\begin{array}{l}\text { Frequência de corte = menor frequência para gerar o efeito fotoelétrico; Função } \\
\text { trabalho = diferença entre energia de vácuo e energia cinética; Potencial de Corte }= \\
\text { ddp que faz voltar para a placa o fotoelétron mais rápido. (A12) }\end{array}$ \\
\hline
\end{tabular}

Deste segundo dia de Organização do Conhecimento foi possível observar que os alunos se interessaram mais e se arriscaram até em prever alguns resultados. Um dos alunos chegou a dizer: "Tá vendo, é possível gostar de Física!". Mesmo não tendo oportunidade de manipular a simulação, os alunos pareceram entender melhor o fenômeno e, assim, pudemos aprofundar um pouco mais o conteúdo. Com isso, a discussão ficou mais interessante, com mais alunos participando e criando soluções para os problemas sugeridos pelo professor. As respostas demonstraram uma sensível evolução na aprendizagem, pois os alunos conseguiram definir mais precisamente o efeito fotoelétrico e os conceitos de frequência de corte e potencial de corte, compreenderam a dependência da frequência para ocorrer o fenômeno confrontando com o pensamento clássico e passaram a entender melhor o modelo proposto por Einstein, visto que um dos alunos usou até uma analogia para responder a uma das questões. Dessa forma, a etapa de Organização do Conhecimento foi cumprida, visto que trabalhamos os conteúdos e conceitos

${ }^{2}$ Analogia feita por Einstein para explicar a natureza da luz (onda x partícula). 


\section{DEDebates

necessários para a compreensão do efeito fotoelétrico, utilizando variadas fontes e recursos didáticos, além de fornecer subsídios aos alunos através das atividades propostas e da simulação computacional, para que eles adquirissem a capacidade de solucionar problemas e prever resultados.

No quarto e último dia, referente à fase da Aplicação do Conhecimento, utilizamos outra simulação computacional, um objeto educacional produzido pela Secretaria de Educação do Estado da Bahia em parceria com a Universidade do Estado da Bahia cujo nome é "Física e o Cotidiano / Efeito Fotoelétrico"3. Esse recurso contém um desafio que consiste em completar circuitos de dispositivos cujo funcionamento está associado ao efeito fotoelétrico. Dentre os dispositivos estão, nesta ordem: despertador inteligente, porta automática, armadilha, poste de iluminação e alarme de presença. Para esse momento, optamos por dividir os estudantes da turma em quatro grupos e levamos um computador portátil com a simulação previamente instalada para eles realizarem o desafio. Como a atividade foi realizada por um grupo de cada vez, optamos pela montagem de apenas dois dos cinco dispositivos disponíveis para que houvesse tempo de realizar as outras atividades planejadas. A preparação e execução desta atividade consumiram os primeiros 50 minutos da aula.

O desempenho de cada grupo, que foi definido de forma livre pelos próprios estudantes, foi avaliado em termos do número de tentativas e erros na montagem dos circuitos de dois dos dispositivos contidos na simulação computacional, acompanhado das observações realizadas pelo pesquisador durante a realização da atividade: despertador e armadilha. A síntese do resultado da aplicação dessa atividade se encontra no Quadro 4 a seguir.

\footnotetext{
${ }^{3}$ Disponível em: <http://objetoseducacionais2.mec.gov.br/bitstream/handle/mec/14356/open/file/index.html>.
} 
Quadro 4: Síntese do resultado da aplicação da atividade. Fonte: Autores.

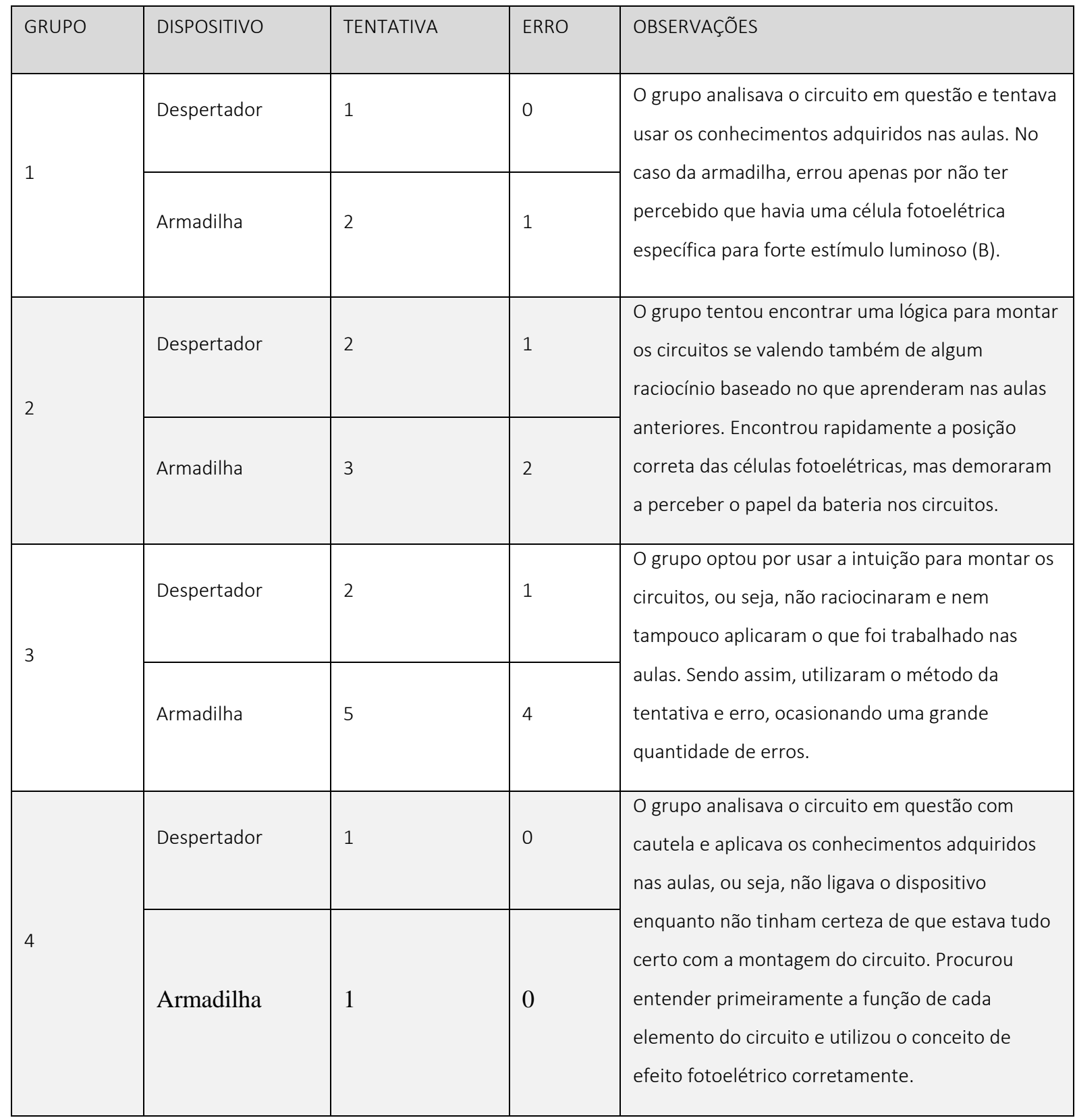

Nos 50 minutos restantes da aula, uma segunda atividade foi realizada, dessa vez fazendo uso de imagens em que o professor propôs a seguinte questão aos alunos: "Escolha um dos sistemas (porta automática, poste e câmera digital) e explique o seu funcionamento relacionando com o efeito fotoelétrico". Ao ler os textos dos alunos, encontramos uma variedade de respostas nas quais, por meio da análise de conteúdo, pudemos inferir alguns padrões de raciocínio que foram divididos em categorias apresentadas no Quadro 5. 
Quadro 5: Categorias de respostas dos alunos quantificadas e exemplificadas. Fonte; Autores.

\begin{tabular}{|c|c|c|}
\hline CATEGORIA & $\mathrm{N}$ & EXEMPLOS \\
\hline $\begin{array}{l}\text { Relacionaram o funcionamento do } \\
\text { dispositivo à emissão de elétrons } \\
\text { devido à incidência de luz em uma } \\
\quad \text { placa metálica. }\end{array}$ & 5 & $\begin{array}{l}\text { A luz incide no metal, gerando elétrons, onde } \\
\text { automaticamente o difusor do poste é disparado, fazendo } \\
\text { acender a luz no poste. (A13) } \\
\text { Está fazendo a emissão de elétrons atravéz de um material } \\
\text { metálico... irá gerar energia (luz) e fará com que o objeto } \\
\text { funcione. (A14) }\end{array}$ \\
\hline $\begin{array}{l}\text { Relacionaram o funcionamento do } \\
\text { dispositivo ao bloqueio ou ausência da } \\
\text { incidência de luz } \\
\text { infravermelho/ultravioleta) em um } \\
\text { receptor. }\end{array}$ & 11 & $\begin{array}{l}\text { A porta automática possui um radar que incide a luz } \\
\text { intravermelha a qual incide diretamente em um receptor } \\
\text { mantendo a porta em seu estado de repouso, quando algo } \\
\text { impede essa transmição da luz para o receptor a porta sai } \\
\text { do seu estado de repouso. (A11) } \\
\text { Os raios ultravioletas que são emitidos pelo sol incide em } \\
\text { um dispositivo que fica atrás do poste fazendo com que ele } \\
\text { se apague. Ao anoitecer, o dispositivo não recebe mais os } \\
\text { raios ultravioletas. (A4) }\end{array}$ \\
\hline $\begin{array}{l}\text { Relacionaram o funcionamento do } \\
\text { dispositivo à existência de um sensor } \\
\text { de radiação (infravermelha/solar). }\end{array}$ & 3 & $\begin{array}{l}\text { O sensor infravermelho, relacionado com o efeito } \\
\text { fotoelétrico, detecta quando alguém ou alguma coisa irá } \\
\qquad \text { passar pela porta. (A15) } \\
\text { Existe um dispositivo que "sente" a presença da luz solar } \\
\text { durante o dia. (A16) }\end{array}$ \\
\hline $\begin{array}{c}\text { Relacionaram o funcionamento do } \\
\text { dispositivo ao calor emitido por algum } \\
\text { corpo }\end{array}$ & 3 & $\begin{array}{c}\text { Durante o dia o sol aquece a lâmpada. (A5) } \\
\text { O efeito fotoelétrico do poste ocorre a partir de sua } \\
\text { temperatura, absorve calor e energia. (A17) }\end{array}$ \\
\hline Outras explicações & 2 & $\begin{array}{l}\text { Os postes que iluminam a noite as ruas possuem um } \\
\text { sistema que é responsável por armazenar a luz proveniente } \\
\text { do sol durante o dia. (A2) } \\
\text { A radiação do sol emite sinais que ao entrar em contato } \\
\text { com o poste a luz é desligada. (A10) }\end{array}$ \\
\hline
\end{tabular}

A partir da análise das respostas dos estudantes nesta última etapa, concluímos que a maioria dos alunos (16) souberam descrever, mesmo que de forma 
parcial, o funcionamento dos sistemas. Dessa forma, podemos afirmar que um dos objetivos do trabalho, que era dar aplicabilidade aos conhecimentos adquiridos nas aulas de física, foi atingido. Ou seja, as discussões e abordagens sobre o tema em sala de aula contribuíram para que os alunos construíssem o seu próprio entendimento e, assim, pudessem formular uma explicação com base científica para a questão apresentada pelo professor. No entanto, desses 16 alunos apenas cinco souberam explicar de que maneira o efeito fotoelétrico pode ser utilizado para fazer funcionar os mais variados sistemas. Ao citar a emissão de elétrons a partir da incidência de radiação eletromagnética em uma placa metálica, eles perceberam que um circuito elétrico pode ser alimentado quando ocorre o efeito fotoelétrico.

Podemos observar também que certos alunos utilizaram os termos radiação, infravermelho e ultravioleta, demonstrando a assimilação de alguns conceitos como espectro da radiação eletromagnética e o transporte de energia através da luz. Entretanto, houve respostas completamente equivocadas utilizando conceitos que não influenciavam na situação, como, por exemplo, o calor. A fase de Aplicação do Conhecimento, que finaliza a sequência didática, mostrou que, de uma maneira geral, houve pouca conexão por parte dos alunos entre os conceitos aprendidos durante as aulas com as situações apresentadas pelo professor. As respostas dadas por esses estudantes nas atividades realizadas confirmaram alguma evolução na aprendizagem do tema, porém dissociada da sua aplicação na realidade. Essa dicotomia entre teoria e prática ainda representa um grande desafio para os professores, pois persistiu neste trabalho apesar da metodologia conter diversos recursos e estratégias. Uma possível especulação para isso reside no fato da impossibilidade dos alunos terem usado eles mesmo a simulação, criando um ritmo próprio de aprendizagem ao terem que pensar no funcionamento dos dispositivos a partir do conceito do efeito fotoelétrico. 


\section{CONSIDERAÇÕES FINAIS}

Ao realizar este trabalho buscamos contribuir para a inserção de conteúdos de FMC no EM e discutirmos a importância de acrescentar essa parte da física nos currículos escolares, após identificarmos, por meio de um levantamento, que a abordagem desses assuntos ainda se apresenta problemática, com destaque para a complexidade dos conceitos e, principalmente, a falta de preparo do professor. Apesar da preocupação por parte dos pesquisadores em inserir FMC no EM, ainda é pequeno o número de trabalhos que sugerem estratégias didáticas para trabalhar esses assuntos, principalmente em se tratando do efeito fotoelétrico, o que nos levou a fazê-lo tópico desta pesquisa. Isso não significa necessariamente produzir mais uma simulação, mais uma animação nem mais qualquer outro recurso, mas sim problematizar e investigar estratégias didáticas que levem em consideração a aprendizagem da física que possa promover de fato uma alfabetização científica e não corrobore para a ojeriza que as pessoas têm da física em suas memórias da etapa de escolarização dessa disciplina. Justamente por isso optamos por não desenvolver uma "inovação" como produto educacional, já que encontramos na internet recursos como as simulações computacionais utilizadas na sequência didática que atendem satisfatoriamente o processo de ensino e aprendizagem do efeito fotoelétrico.

É consensual que o efeito fotoelétrico não pode estar ausente em qualquer currículo que contemple a FMC dentre os conteúdos de física nas escolas, fato hoje praticamente inquestionável. Mas qual a melhor forma de abordagem: trabalhar com história e filosofia da ciência? Trabalhar com analogias clássicas? Explorar a aplicação desses conceitos na criação da tecnologia que usamos no nosso cotidiano? Neste trabalho utilizamos todas essas formas distribuídas nas três etapas correspondentes à dinâmica dos 3MP e obtivemos resultados positivos, em que os 


\section{DEDebates

conhecimentos dos alunos foram evoluindo gradativamente. Consideramos que a introdução de simulações computacionais potencializou a sequência didática e foi importante para minimizar problemas de abstração, muito comuns quando se trabalha com o efeito fotoelétrico, entre outros da FMC, no EM. Utilizamos duas simulações, uma delas após a aula expositiva do conteúdo, para demonstrar e explicar melhor a teoria, e a outra na aula seguinte, para aplicar o que aluno aprendeu. Isso fez com que as aulas se tornassem mais dinâmicas e até mesmo divertidas, prendendo a atenção dos alunos por mais tempo e promovendo uma maior participação individual e em grupo.

Ao contrário de Braga, Killner e Araújo (2017) que não observaram diferenças significativas de aprendizagem quando se usa a simulação computacional no início ou no final da estratégia didática, acreditamos que, para trabalhar o tópico efeito fotoelétrico, a simulação gere melhores resultados quando utilizada após a abordagem sistemática, ou seja, primeiro deve-se ensinar os conceitos e a teoria envolvida para depois usar a simulação computacional com o objetivo de consolidar a aprendizagem. Isso pode ser explicado pelo fato de que a simulação reproduz um fenômeno abstrato, de certo modo inédito e de difícil percepção da sua aplicabilidade à primeira vista para os alunos, uma vez que ainda se mantêm concepções baseadas no senso comum ou não científicas acerca do fenômeno.

É importante destacar que os alunos, através das suas respostas aos questionários aplicados, demonstraram evolução na aprendizagem dos conceitos envolvidos e uma razoável compreensão do modelo proposto por Einstein para explicar o fenômeno. Antes da intervenção didática, por exemplo, definiam a luz como uma forma de energia que poderia inclusive ser armazenada. Além disso, não conseguiam enxergar a luz como uma onda e muito menos imaginar a sua natureza dual. Conheciam muito superficialmente os conceitos de frequência, comprimento 
de onda e energia. Porém, no decorrer das aulas e principalmente através do simulador, os alunos começaram a entender a função de cada uma dessas grandezas, associar as cores às diferentes faixas de frequências e finalmente perceberam que a luz possuía todos os elementos de uma onda, definindo-a como uma radiação de natureza eletromagnética. De posse desses conceitos melhores assimilados, os alunos foram capazes até mesmo de sugerirem ações ao professor para a resolução de problemas que o mesmo colocava durante a manipulação da simulação. Estas talvez tenham sido as maiores conquistas da estratégia didática aplicada, a concessão de autonomia aos alunos para que estes chegassem às suas próprias conclusões e o fornecimento de subsídios para que eles se sentissem capazes de tomarem decisões.

\section{REFERÊNCIAS (CABEÇALHO 1, SEM NÚMERO)}

ALBUQUeRQUE, K. B.; SANTOS, P. J. S.; KAIANA, G. F. Os Três Momentos Pedagógicos como metodologia para o ensino de Óptica no Ensino Médio: o que é necessário para enxergarmos? Caderno Brasileiro de Ensino de Física, v.32, n.2, p.461-482, 2015.

BARDIN, L. Análise de Conteúdo. Lisboa: Edições 70, 2009.

BRAGA, A. S.; KILLNER, G. I.; ARAÚJO, F. G. O uso de simuladores computacionais como recurso didático nas aulas de Física: Antes ou depois? In: SIMPÓSIO NACIONAL DE ENSINO DE FÍSICA, 22., 2017, São Carlos. Atas... São Paulo: SBF, 2017.

BROCKINGTON, G.; PIETROCOLA, M. Serão as regras da Transposição Didática aplicáveis aos conceitos de Física Moderna? Investigações em Ensino de Ciências, v.10, n.3, p.387-404, 2005.

CARDOSO, S. O. O.; DICKMAN, A. G. Simulação computacional aliada à teoria da aprendizagem significativa: Uma ferramenta da aprendizagem para ensino e aprendizagem do efeito fotoelétrico. Caderno Brasileiro de Ensino de Física, v.29, n.2, 
p.891-934, 2012.

CAvalcante, M. A.; ROdRIgues, T. T.T.; BUEnO, D. A. Controle Remoto: Princípio de funcionamento (parte 1 de 2). Caderno Brasileiro de Ensino de Física, v.30, n.3, p.554-565, 2013.

DELIZOICOV, D. Didática Geral. 1 ed. Florianópólis: UFSC/EAD/CED/CFM, 2008.

GEHLEN, S. T.; MALDANER, O. A.; DELIZOICOV, D. Momentos pedagógicos e as etapas da situação de estudo: complementaridades e contribuições para a Educação em Ciências. Ciência \& Educação, v.18, n.1, 2012.

MEDEIROS, A.; MEDEIROS, C. F. Possibilidades e Limitações das Simulações Computacionais no Ensino da Física. Revista Brasileira de Ensino de Física, v.24, n.2, 2002.

MINAYO, M. C. de S. O desafio do conhecimento. 11 ed. São Paulo: Hucitec, 2008.

MONTEIRO, M. A.; NARDI, R. A Física Moderna e Contemporânea no Ensino Médio e a Formação de Professores: racionalidade técnica ou racionalidade comunicativa?. In: SIMPÓSIO NACIONAL DE ENSINO DE FÍSICA, 18., 2009, Vitória. Atas... São Paulo: SBF, 2009.

OSTERMANN, F.; MOREIRA, M. A. Uma revisão bibliográfica sobre a área de pesquisa Física Moderna e Contemporânea no ensino médio. Investigações em Ensino de Ciências, v.5, n.1, 2000.

Atualização do currículo de física na escola de nível médio: um estudo dessa problemática na perspectiva de uma experiência em sala de aula e da formação inicial de professores. Caderno Brasileiro de Ensino de Física, v.18, n.2, p.135-151, 2001.

PAULO, I. J. C. de; MOREIRA, M. A.. O problema da linguagem e o ensino da mecânica 
quântica no nível médio. Ciência \& Educação, v.17, n.2, p.421-434, 2011.

PEREIRA, M. V.; MOREIRA, M. C. do A. Atividades prático-experimentais no ensino de Física. Caderno Brasileiro de Ensino de Física, v.34, n.1, 2017.

RIO DE JANEIRO. Currículo Mínimo - Física. Rio de Janeiro: Secretaria de Estado de Educação do Rio de Janeiro, 2012.

SABINO, A.; PIETROCOLA, M. Saberes docentes desenvolvidos por professores do ensino médio: um estudo de caso com a inserção da Física Moderna. Investigações em Ensino de Ciências, v.21, n.2, 2016.

SILVA, J. R. N.; ARENGHI, L. E. B.; LINO, A. Por que inserir física moderna e contemporânea no ensino médio? Uma revisão das justificativas dos trabalhos acadêmicos. Revista Brasileira de Ensino de Ciência e Tecnologia, v.6, n.1, p.69-83, 2013.

SILVA, L. F.; ASSIS, A. Física Moderna no Ensino Médio: um experimento para abordar o Efeito Fotoelétrico. Caderno Brasileiro de Ensino de Física, v.29, n.2, p.313-324, 2012.

SILVA, R. S.; ERROBIDART, N. C. G. Sobre as pesquisas relacionadas ao ensino do efeito fotoelétrico. Caderno Brasileiro de Ensino de Física, v.32, n.3, p.618-639, 2015.

SOARES, A. A.; MORAES, L. E.; OLIVEIRA, F. G. Ensino de matéria e radiação no ensino médio com o auxílio de simuladores interativos. Caderno Brasileiro de Ensino de Física, v.32, n.3, p.915-933, 2015.

Recebido em: Julho de 2017. Publicado em: Agosto de 2017. 